\title{
A Unique Mycobacterium Species Isolated from an Epizootic of Striped Bass (Morone saxatilis)
}

\author{
Martha W. Rhodes,* Howard Kator,* Shaban Kotob,* Peter van Berkum, $\dagger$ \\ Ilsa Kaattari,* Wolfgang Vogelbein,* Margaret M. Floyd,‡ W. Ray B utler,; \\ F rederick D. Quinn,‡ Christopher Ottinger,§ and E mmett Shotts§ \\ *Virginia Institute of Marine Science, College of William and Mary, Gloucester Point, \\ Virginia, USA; †U. S. Department of Agriculture, Beltsville, Maryland, USA; ¥Centers \\ for Disease Control and Prevention, Atlanta, Georgia, USA; and §National \\ Fish Health Research Laboratory, Kearneysville, West Virginia, USA
}

\begin{abstract}
We isolated a Mycobacterium sp. resembling Mycobacterium marinum and M. ulcerans from diseased striped bass (Morone saxatilis) during an epizootic of mycobacteriosis in the Chesapeake Bay. This isolate may represent an undescribed Mycobacterium species, based on phenotypic characteristics and comparative 16S rRNA gene sequence.
\end{abstract}

Natural aquatic environments are recognized sources of mycobacteria known to cause disease in both humans and fish. Although Mycobacterium marinum is considered the primary causative agent of fish mycobacteriosis, seven Mycobacterium species associated with tubercle granulomas in aquarium, cultured, and wild fish populations have been described: $M$. abscessus, $M$. chelonae, $M$. fortuitum, M. marinum, $M$. neoaurum, $M$. scrofulaceum, and $M$. simiae $(1,2)$. All these species cause disease in humans $(3,4)$. Primary dinical syndromes include skin and soft-tissue infections, cervical lymphadenitis, pulmonary disease, and disseminated infections, the last generally being limited to immunocompromised persons. Human mycobacteriosis following occupational or recreational exposure to the marine environment is frequently associated with trauma such as wounds from handling fish and has been attributed primarily to $M$. marinum (5). Consequently, the discovery of an undescribed Mycobacterium species associated with an epizootic of mycobacteriosis in striped bass (Moronesaxatilis) warrants recognition and additional study.

Mycobacteriosis in fish is a subacute to chronic wasting disease known to affect some 167 freshwater and saltwater species (2). Internal signs of the disease vary according to fish species but typically include granulomas in the spleen, kidney, and liver. External manifestations include scale loss accompanied by hemorrhagic lesions penetrating the musculature in advanced cases. Recently, an ongoing epizootic of mycobacteriosis in striped bass (Morone saxatilis) from the Chesapeake Bay was described (Vogelbein W et al., unpub. data). Previous outbreaks of mycobacteriosis in wild striped bass have occurred in Pacific estuaries (6). During the Chesapeake Bay epizootic, we isolated a variety of mycobacteria associated with skin and visceral lesions that included a unique group of slowly growing nonpigmented isolates. We describe one of these isolates, which has specific characteristics similar to those of M. marinum and M. ulcerans.

Address for correspondence: Martha W. Rhodes, Department of Environmental Sciences, Virginia Institute of Marine Science, College of William and Mary, PO Box 1346, Gloucester Point, VA 23062, USA; fax: 804-684-7186; email: martha@vims.edu
Striped bass ( $n=20$ ) we examined included asymptomatic and symptomatic fish with skin ulcerations (Figure) verified histologically to exhibit granulomatous inflammation associated with acid-fast bacilli. All fish were caught in the Chesapeake Bay or one of its tributaries (the J ames, Potomac, or Rappahannock rivers). Skin and spleen samples from necropsied specimens were processed for routine paraffin histology, sectioned at $5 \mu \mathrm{m}$, and stained with hematoxylin and eosin. Selected sections were stained using ZiehlNeelsen's method for acid-fast bacteria (7). Excised internal tissues (predominately spleen) were homogenized in phosphate buffer using a Ten Broeck tissue grinder and inoculated directly onto culture media or after treatment with one of the following disinfectants (Vogel bein et al., unpub. data): $0.3 \%$ Zephiran (Sanofi Winthrop Pharmaceuticals, New York, NY), $2 \% \mathrm{NaOH}$, or $2 \% \mathrm{HCl}$. Homogenates were inoculated onto Löwenstein-J ensen slants and plates of brain heart infusion agar containing 5\% sheep red blood cells and Middlebrook $7 \mathrm{H} 10$ agar with albumin-dextrose-catalase enrichment. I nitially inoculated media were incubated at $30^{\circ} \mathrm{C}$ for a minimum of 2 months. Because some isolates exhibited poor growth, a second incubation temperature

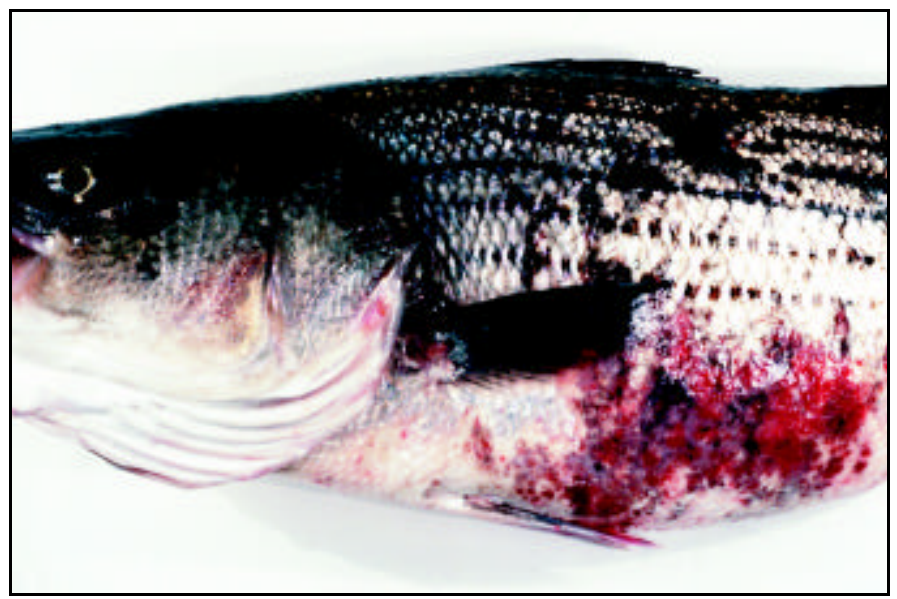

Figure. Skin ulcers typical of mycobacteriosis in striped bass (Morone saxatilis) from the Chesapeake Bay. 


\section{Dispatches}

$\left(23^{\circ} \mathrm{C}\right)$ was used for primary media inoculated with tissue homogenates.

Purified isolates were characterized phenotypically by traditional methods (8) with incubation at $23^{\circ} \mathrm{C}$. Mycolic acids were analyzed by a standardized method for mycobacteria by using reverse-phase high-performance liquid chromatography (HPLC) with UV detection $(9,10)$.

Polymerase chain reaction (PCR) assay and sequence analysis of the 16S rRNA gene were used to characterize one of the slow-growing, nonpigmented mycobacteria, hereafter called isolate M175. This isolate is deposited in the American Type Culture Collection (ATCC), Rockville, MD, as ATCC 700981. The 16S rRNA gene was amplified in 120- $\mu \mathrm{L}$ volumes (11) by using cycle conditions described by van Berkum and Fuhrmann (12). Primers (forward, M16SA, 5'-CGC TGG CGG CGT GCT TA-3' and reverse, M16SB, 5'-ACG GCT ACC TTG TTA C-3') were specifically designed for the amplification of mycobacterial 16S rRNA genes. The PCR buffer $(\mathrm{pH}$ 8.5) contained $60 \mathrm{mM}$ Tris- $\mathrm{HCl}, 15 \mathrm{mM}$ $\left(\mathrm{NH}_{4}\right) 2 \mathrm{SO}_{4}$, and $1.5 \mathrm{mM} \mathrm{MgCl}$; control reactions without template were included. After purification of PCR products (QIAquick Spin columns, Qiagen Inc., Chatsworth, CA), amplicons were sequenced with a Perkin-Elmer 377 DNA Sequencer in combination with a Dye Deoxy Terminator Cycle Sequencing Kit (Perkin-Elmer, Foster City, CA) $(11,12)$.

Granulomatous inflammation was confirmed histologically in spleens of 18 of the 20 fish. Severity of the infection based on the abundance and size of splenic granul omas varied from mild to severe. Skin ulcers were evident in 13 specimens. Granulomatous inflammation was generally associated with acid-fast bacilli in selected stained sections.

Colony development from homogenized tissue was slow, requiring 4 to 6 weeks' incubation at $23^{\circ} \mathrm{C}$ on the preferred medium, Middlebrook 7H 10 agar. I solate M175 showed little or no growth at $30^{\circ} \mathrm{C}$ and none at $37^{\circ} \mathrm{C}$. Rough nonpigmented colonies were flat with an irregular margin and yielded aggregates of acid-fast nonbranching rods. Isolate M 175 was negative for growth on MacConkey agar and LöwensteinJ ensen with $5 \% \mathrm{NaCl}$, arylsulfatase, beta-galactosidase, nitrate reductase, semiquantitative catalase, Tween 80 hydrolysis, and Tween opacity. Weak positive reactions for catalase activity after treatment at $68^{\circ} \mathrm{C}$ and pyrazinamidase after extending incubation to 14 days were observed. I solate M175 was positive for tellurite reduction, niacin production, and urease. Colonies did not produce pigment after exposure to light for several hours or after prolonged exposure for several days. Based on the aforementioned characteristics, this isolate could not be assigned to an existing species.

The M175 mycolic acid pattern consisted of a single cluster of eight peaks that visually resembled reference patterns (10) for species of the M. tuberculosis complex. However, M175 mycolic acid peaks did not superimpose with peaks of $M$. tuberculosis after alignment with the internal size standard. Peak elution times for M 175 were suggestive of more polar, shorter, carbon chain-length mycolic acids than those found in M. tuberculosis complex species. Comparisons of the M175 pattern with the Mycobacterium HPLC mycolic acid database at the Centers for Disease Control and Prevention confirmed a unique pattern suggestive of a new species of mycobacteria.

The sequence of the PCR product of the 16S rRNA gene from Mycobacterium isolate M175 was 1,494 nt long. This sequence was deposited in GenBank and was given accession number AY 005147. Blast searches of GenBank yielded high sequence similarities of $99.2 \%$ to $M$. marinum (13) and $M$. ulcerans (14) and of $98.7 \%$ to M. bovis (15) and M. tuberculo-

Table. Comparison of distinguishing phenotypic features of Mycobacterium sp. isolate M175 with genetically (16S rRNA) similar Mycobacterium spp. (M. bovis, M. marinum, M. tuberculosis, and M. ulcerans)

\begin{tabular}{|c|c|c|c|c|c|}
\hline Characteristic & $\begin{array}{l}\text { Mycobacterium sp. (fish } \\
\text { isolate M 175) }\end{array}$ & M. bovis & M. marinum & M. tuberculosis & M. ulcerans \\
\hline $\begin{array}{l}\text { Optimum growth } \\
\text { temperature }\left({ }^{\circ} \mathrm{C}\right)\end{array}$ & $<30$ & 37 & 30 & 37 & 30 \\
\hline Colony morphology & $\mathrm{R}$ & $\mathrm{R}$ & $\mathrm{S}$ & $\mathrm{R}$ & $S / R$ \\
\hline Pigmentation & $\mathrm{N}$ & $\mathrm{N}$ & $\mathrm{P}$ & $\mathrm{N}$ & $\mathrm{N}$ \\
\hline $\begin{array}{l}\text { Arylsulfatase } \\
3 \text { days } \\
14 \text { days }\end{array}$ & $\begin{array}{l}- \\
-\end{array}$ & $\begin{array}{l}- \\
-\end{array}$ & $\begin{array}{l}V \\
+\end{array}$ & $\begin{array}{l}- \\
-\end{array}$ & $\begin{array}{l}- \\
+\end{array}$ \\
\hline Niacin & + & - & $-N$ & + & $-N$ \\
\hline Nitrate reduction & - & - & - & + & - \\
\hline $\begin{array}{l}\text { Pyrazinamidase } \\
7 \text { days }\end{array}$ & - & - & + & + & - \\
\hline Tween hydrolysis & - & V & + & v & - \\
\hline Urease & + & + & + & + & - \\
\hline
\end{tabular}

Source: Data for known species cited from references 17 and 18.

Abbreviations: $d=$ days; $N=$ nonpigmented; $\mathrm{P}=$ photochromogenic; $\mathrm{R}=$ rough; $\mathrm{S}=$ smooth; $+=$ at least $85 \%$ strains positive; - =đ least $85 \%$ negative; $\mathrm{V}=$ variable. 


\section{Dispatches}

sis (16). High sequence similarities between $16 \mathrm{~S}$ rRNA genes of M175 and other Mycobacterium spp. and phenotypic data support the conclusion that M175 belongs within the genus Mycobacterium. However, despite the similarities, the $16 \mathrm{~S}$ gene sequence of M175 differed from M. ulcerans by $11 \mathrm{nt}$ (3 insertions and 8 substitutions [one base of the $M$. ulcerans sequence in GenBank is N]) and from M. marinum by $10 \mathrm{nt}$ (4 insertions, 6 substitutions [one base of the M. marinum sequence in GenBank is N ]). Based on sequence differences and contrasting phenotypic characteristics (Table), we conclude that isolate M175 appears to belong to a new, previously undescribed species of Mycobacterium (19). Comparative genetic studies of $M$. ulcerans and $M$. marinum based on 16S rRNA sequence analysis have shown very close relationships between these species despite contrasting phenotypic profiles (20-24). The presence of two DNA insertion sequences, IS2404 and IS2606, in M. ulcerans but not in M. marinum has been used to distinguish the former (22-25).

The public health significance of this unique Mycobacterium species is not known. Frequently, mycobacterial disease in fish and cutaneous infections in humans are diagnosed on the basis of clinical presentation and generally attributed to M. marinum. Isolation of the causative agent either is not attempted or is unsuccessful, possibly because of loss of viability during specimen decontamination, inappropriate culture conditions, lack of technical experience with mycobacteria, or the prevailing assumption that detection of acid-fast rods is synonymous with a diagnosis of $\mathrm{M}$. marinum. Consequently, the extent of environmentally acquired human infections caused by Mycobacterium species is not known. Studies to investigate the clinical importance of isolates obtained from persons exposed to marine or estuarine sources would provide data on which to evaluate the public health import of these isolates.

As in the present study, environmental mycobacteria may have lower temperature optima and not grow well on traditional media such as Löwenstein-J ensen. However, a preference for low temperature does not necessarily negate their ability to cause disease in humans, as demonstrated by disseminated infections caused by $M$. marinum and $M$. haemophilum or ulcerative skin disease caused by M. ulcerans. An epizootic of mycobacteriosis in striped bass, possibly the most important recreational fish in the Chesapeake Bay, could serve as a reservoir for transmission of mycobacterial infections to humans.

Laboratory challenge studies using striped bass are in progress to evaluate the pathogenicity of isolate M 175. Additional research is needed to understand the persistence, distribution, and ecology of these mycobacterial isolates in natural waters, particularly with regard to their transmission to fish. Furthermore, this study also underlines a need to isolate and identify mycobacteria responsible for nontuberculosis infections in humans. This information is essential to determine the extent of human mycobacteriosis associated with occupational and increasingly popular recreational exposure to the natural aquatic environment.

\section{Acknowledgments}

The authors thank Dana Booth, Dave Zwerner and Patrick Elia for their excellent technical assistance.

Funding was obtained in part from the Virginia Marine Resource Commission, Commonwealth of Virginia, and the Virginia
Institute of Marine Science, College of William and Mary (contribution no. 2368 of the Virginia Institute of Marine Science).

Ms. Rhodes is a microbiologist in the Department of Environmental Sciences, Virginia Institute of Marine Science. Her research interests focus on public health microbiology related to the estuarine environment.

\section{References}

1. Lansdell WB, Dixon B, Smith N, Benjamin L. I solation of several Mycobacterium species from fish. J ournal of Aquatic Animal Health 1993;5:73-6.

2. Chinabut S. Mycobacteriosis and nocardiosis. In: Woo PTK, Bruno DW, editors. Fish diseases and disorders. Vol 3. Viral, bacterial and fungal infections. Wallington, UK: CAB International; 1999. p. 319-40.

3. Wayne LG, Sramek HA. Agents of newly recognized or infrequently encountered mycobacterial diseases. Clin Microbiol Rev 1992:5:1-25.

4. Falkinham J O III. Epidemiology of infection by nontuberculous mycobacteria. Clin Microbiol Rev 1996;9:177-215.

5. Wolinsky E. Mycobacterial diseases other than tuberculosis. Clin Infect Dis 1992;15:1-12.

6. Sakanari J A, Reilly CA, Moser M. Tubercular lesions in Pacific coast populations of striped bass. Transactions of the American Fisheries Society 1983;112:565-6.

7. Luna LG, editor. Manual of histologic staining methods of the Armed F orces Institute of Pathology. New York: McGraw-Hill; 1968.

8. Lutz B. Section 3. Mycobacteriology. 3.12. Identification tests for mycobacteria. In: I senburg HD, editor. Clinical microbiology procedures handbook. Vol 1. Washington: American Society for Microbiology; 1992. p. 3.12.1-29.

9. Butler WR, Kilburn J O. Identification of major slowly growing pathogenic mycobacteria and Mycobacterium gordonae by high performance liquid chromatography of their mycolic acids. J Clin Microbiol 1988;26:50-3.

10. Butler WR, Floyd MM, Silcox V, Cage G, Desmond E, Duffey PS, et al. Standardized method for HPLC identification of mycobacteria. HPLC users group in cooperation with Centers for Disease Control and Prevention. Atlanta: U.S. Public Health Service, CDC; 1996.

11. van Berkum P, Beyene D, Eardly BD. Phylogenetic relationships among Rhizobium species nodulating the common bean Phaseol us vulgaris L. Int J Syst Bacteriol 1996;46:240-4.

12. van Berkum $\mathrm{P}, \mathrm{Fuhrmann} \mathrm{JJ}$. Evolutionary relationships among the soybean bradyrhizobia reconstructed from 16S rRNA gene and internally transcribed spacer region sequence divergence. Int J Syst Evol Microbiol 2000;50:2165-72.

13. Rogall T, Wolters J, Flohr T, Bottger EC. Towards a phylogeny and definition of species at the molecular level within the genus Mycobacterium. Int J Syst Bacteriol 1990;40:323-30.

14. Hofer M, Hirschel B, Kirschner P, Beghetti $M$, Kaelin A, Siegrist CA, et al. Brief report: disseminated osteomyelitis from Mycobacterium ulcerans after a snakebite. N Engl J Med 1993;328:1007-9.

15. Suzuki $Y$, Nagata A, Ono $Y, Y$ amada $T$. Complete nucleotide sequence of the 16S rRNA gene of Mycobacterium bovis BCG. J Bacteriol 1988;170:2886-9.

16. Aranaz A, Liebana E, Gomez-Mampaso E, Galna J C, Cousins D, Ortega A, et al. Mycobacterium tuberculosis subsp. caprae subsp. nov.: a taxonomic study of a new member of the Mycobacterium tuberculosis complex isolated from goats in Spain. Int J Syst Bacteriol 1999;49:1263-73.

17. Witebsky FG, Kruczak-Filipov P. I dentification of mycobacteria by conventional methods. Clin Lab Med 1996;16:569-601.

18. Goodfell ow M, Magee J G. Taxonomy of mycobacteria. In: Gangadharam PRJ, J enkins PA, editors. Mycobacteria I: Basic aspects. New York: Chapman and Hall; 1998. p. 1-71.

19. Lévy-F rébault $V V$, Portaels $F$. Proposed minimal standards for the genus Mycobacterium and for description of new slowly growing Mycobacterium species. Int J System Bacteriol 1992:42:315-23 


\section{Dispatches}

20. Portaels F, Fonteyne P-A, De Beenhouwer H, De Rijk P, Guédénon A, Hayman J , et al. Variability in 3' end of 16S rRNA sequence of Mycobacterium ulcerans is related to geographic origin of isolates. J Clin Microbiol 1996;34:962-5.

21. Tonjum T, Welty DB, J antzen E, Small PL. Differentiation of Mycobacterium ulcerans, M. marinum, and M. haemophilum: mapping of their relationships to $M$. tuberculosis by fatty acid profile analysis, DNA-DNA hybridization, and 16S rRNA gene sequence analysis. J Clin Microbiol 1998;36:918-25.

22. Stinear T, Ross BC, Davies J K, Marino L, Robins-Browne RM, Oppedisano $\mathrm{F}$, et al. Identification and characterization of I S2404 and IS2606: two distinct repeated sequences for detection of Mycobacterium ulcerans by PCR. J Clin Microbiol 1999;37:1018-23.
23. Stinear T, Davies J K, J enkin GA, Portaels F, Ross BC, Oppedisano F, et al. A simple PCR method for rapid genotype analysis of Mycobacterium ulcerans. J Clin Microbiol 2000;38:11482-7.

24. Stinear TP, J enkin GA, J ohnson PDR, Davies J K. Comparative genetic analysis of Mycobacteriumulcerans and Mycobacterium marinum reveals evidence of recent divergence. J Bacteriol 2000;182:6322-30.

25. Ross BC, Marino L, Oppedisano F, E dwards R, Robins-Browne RM, J ohnson PDR. Development of a PCR assay for rapid diagnosis of Mycobacteirum ulcerans infection. J Clin Microbiol 1997;35:1696-700. 